\title{
PENERAPAN SUSTAINABLE DESIGN \\ DALAM PERANCANGAN TAMAN BUDAYA DI KABUPATEN KLATEN
}

\section{Dwi Setiawan}

Prodi Arsitektur Fakultas Teknik Universitas

Teknologi Yogyakarta

setyadwx@gmail.com

\section{Dita Ayu Rani Natalia}

Prodi Arsitektur Fakultas Teknik Universitas Teknologi Yogyakarta

ditaayurani@uty.ac.id

\begin{abstract}
ABSTRAK
Klaten merupakan pusat kota dari Pemerintahan Kabupaten Klaten, Jawa Tengah. Klaten merupakan salah satu bagian dari Karisidenan Surakarta atau merupakan bagian dari lingkup daerah kekuasaan Kasunanan Surakarta. Posisi Klaten berada di tengah - tengah antara pusat kota Solo dan Yogyakarta, menjadikan Klaten sebagai sebuah kabupaten yang sangat kaya akan potensi kebudayaan daerah. Selain itu Klaten memiliki kalender event setiap tahunnya yang diadakan di beberapa daerah Kabupaten Klaten. Taman Budaya adalah suatu ruang yang memiliki fungsi sebagai wadah kegiatan menggelar berbagai pertunjukan sekaligus tempat berkumpul dan bertemu para seniman dan juga sebagai ajang pengenalan dan pelestarian budaya ke generasi mendatang. Perancangan Taman Budaya diawali pengumpulan data dengan menggunakan metode pengumpulan data primer yaitu berupa wawancara, pengamatan, pemetaan lokasi serta dokumentasi, dan metode pengumpulan data sekunder yaitu berupa data dari instansi yang terkait serta studi literatur terhadap jurnal atau karya ilmiah yang berkaitan. Pendekatan konsep sustainable design digunakan sebagai usaha penyatuan bangunan dengan prinsip keberlanjutan budaya, yang meliputi keseimbangan social, ekonomi dan lingkungan. Tiga hal ini menjadi dasar agar terwujudnya kenyamanan, integrasi social di dalam maupun luar bangunan serta pengurangan dampak limbah bangunan terhadap lingkungan. Hasil konsep sustainable design diterapkan secara fungsi ruang, tampak bangunan dengan mempertimbangkan struktur dan utilitas bangunan.
\end{abstract}

KATA KUNCI: Klaten, sustainable design, taman budaya

\section{PENDAHULUAN}

Klaten merupakan pusat kota dari pemerintahan Kabupaten Klaten, Jawa Tengah, yang terdiri dari 26 kecamatan, dengan luas wilayah mencapai 658,22 $\mathrm{km}^{2}$. Klaten merupakan salah satu dari bagian Karisidenan Surakarta atau bagian dari lingkup daerah kekuasaan Kasunanan Surakarta, oleh karena itu setiap adat istiadatnya sama dengan Surakarta. Klaten berada di tengah - tengah antara kota Surakarta dan Yogyakarta. Hal ini menjadikan Klaten sebagai sebuah kabupaten yang sangat kaya akan potensi kebudayaan daerah. Potensi budaya ditunjang oleh keberadaan tempat pariwisata yang terbilang cukup banyak. Terdapat beberapa wisata sejarah berupa candi, dan pabrik gula yang kini menjadi sebuah museum, dan masih dioperasikan. Wisata alam berupa tempat pemandian atau umbul, taman lampion, dan bentuk lain adalah wisata kuliner. Di Klaten setiap tahun diselenggarakan agenda atau event kebudayaan, pertunjukan seni, event kuliner dan lainnya. Bupati Klaten sangat mendukung agenda besar kota kabupaten ini. Program yang dicanangkan bertujuan agar warga Klaten tetap mempertahankan potensi budayanya, dan tidak melupakan kesenian dan budaya yang dimiliki kota Klaten.

Klaten yang diapit oleh dua kerajaan di tanah Jawa, yaitu Kasunanan Surakarta dan Kasultanan Yogyakarta, menjadikan Klaten sangat kaya akan budaya daerah. Peninggalan artefak berupa candi, makam dan peninggalan berupa seni pertunjukan hingga upacara tradisi yang sangat kental akan sarat budaya daerah. Salah satu peninggalan sejarah Klaten berupa candi seperti candi Plaosan yang didirikan ketika bersemayam Raja Wangsa Sailendra bernama Rakai Pikatan, raja yang sama yang mendirikan candi Borobudur. Peninggalan sejarah lainnya yaitu makam Sunan Tembayat yang dalam sejarahnya diutus oleh Sunan Kalijaga untuk menyebarkan agama Islam. Klaten juga memiliki beberapa upacara tradisi yang sudah berlangsung sejak jaman penyebaran agama Islam yang pada masa itu masyarakat masih banyak menganut kepercayaan pada pohon dan batu besar. Salah satu upacara tradisi tersebut yaitu Yaaqowiyuu, upacara tradisi yang dilakukan untuk mengenang jasa Ki Ageng Gribig, seorang tokoh ulama penyebar agama Islam di Jawa yang menetap dan meninggal di Jatinom, Klaten. Selain upacara tradisi, potensi budaya yang ada 
di Kabupaten Klaten adalah desa wisata yang menawarkan edukasi mengenai beberapa budaya yang ada seperti kerajinan keramik, wayang, gamelan, pertunjukan tradisional, batik dan lain-lain. Kabupaten Klaten menyimpan banyak potensi budaya daerah sehingga dapat menjadi destinasi wisata budaya.

Ketersediaan wadah untuk pengembangan potensi budaya akan menarik bila diwujudkan melalui pendekatan sustainable design. Tulisan ini bertujuan menyususn konsep perencanaan Taman Budaya di Kabupaten Klaten yangdapat dipertanggungjawabkan dalam lingkungan bangunan dan memberikan dampak positif terhadap pengguna. Konsep sustainable dapat menciptakan suasana nyaman, dimana seniman mampu menyatu dengan lingkungan yang alami, sehingga dapat berkonsentrasi menghasilkan karya seni. Prinsip sustainable atau berkelanjutan meliputi keseimbangan ekologis, sosial, dan ekonomi. Tiga hal ini menjadi dasar agar terwujudnya kenyaman, interaksi sosial di dalam atau di luar bangunan, dan pengurangan dampak pembuangan limbah bangunan terhadap lingkungan. Penerapan konsep dalam bangunan berupa suasana nyaman yang dibuat dalam bangunan dengan penerapan green building dari segi material, sistem pencahayaan, dan sistem pengelolaan air.

Jack A. Kramers (dalam Kurniasih, 2013, p.13) menyebutkan bahwa "Sustainable Architecture is responce and an expression of celebration of our existence and respect for the world arround us". Arsitektur berkelanjutan merupakan suatu respon dan ekspresi dari keberadaan serta rasa peduli terhadap sekitar.

Jason F. Mc Lennan (2004) mendefinisikan sustainable design sebagai sebuah filosofis untuk rancangan yang menghasilkan kualitas lingkungan buatan secara maksimal, pada saat bersamaan meminimalkan atau mengeliminasi dampak negatifnya terhadap lingkungan alam. Sustainable design adalah sebuah pendekatan untuk merancang dan bukan sebuah penilaian estetika. Tujuan utama pendekatan ini adalah untuk meningkatkan atau menciptakan kualitas bangunan yang lebih baik untuk manusia, dan tempat yang lebih baik untuk dihuni. Sustainable design juga menekankan pencarian solusi rancangan yang seimbang terhadap permasalahan lingkungan, kenyamanan, estetika, serta biaya.

\section{METODE PERANCANGAN}

Metode perancangan diawali dengan pengumpulan data, analisisi data, dan menginterpretasikan data pada bagian akhir berupa desain perencanaan dan perancangan yang mengacu pada hasil analisis data.

Metode pengumpulan data menggunakan data primer dan sekunder. Pengumpulan data primer didapat secara langsung dari hasil pengamatan di lokasi site di daerah Kabupaten Klaten. Teknik yang dilakukan yaitu melakukan wawancara dengan pegawai Dinas Pariwisata Kebudayaan Kabupaten Klaten, mengamati lokasi yang akan dibangun, memetakan titik lokasi site, dan mendokumentasikan kondisi site dengan lingkungan sekitar.

Pada pengumpulan data sekunder dilakukan dengan studi literatur dan studi preseden arsitektur. Studi literatur melalui buku-buku dan referensi yang berkaitan dengan permasalahan yang dibahas. Selain itu pengambilan data juga digunakan media cetak ataupun media elektronik baik teori, pendapat ahli, serta peraturan dan kebijakan pemerintah daerah menjadi dasar perancangan. Studi preseden arsitektur dilakukan dengan mereview bangunan yang telah ada dengan fungsi dan konsep pendekatan yang sama. Hal tersebut untuk membandingkan bangunan baik secara fungsi, fasilitas, bentuk, struktur dan sebagainya untuk mendapat sebuah kesimpulan desain yang nantinya dapat menjadi acuan dalam Perancangan Taman Budaya di Kabupaten Klaten.

\section{HASIL PERANCANGAN}

\section{Analisis}

Analisis sangat diperlukan untuk merancang suatu bangunan agar dapat tercipta sesuai kebutuhan pengguna.

1. Analisis dan respon matahari berpengaruh ke dalam dan luar bangunan yang dimana kondisi site bagian barat, selatan, barat, dan utara tidak terhalang oleh bangunan (lihat Gambar 1).

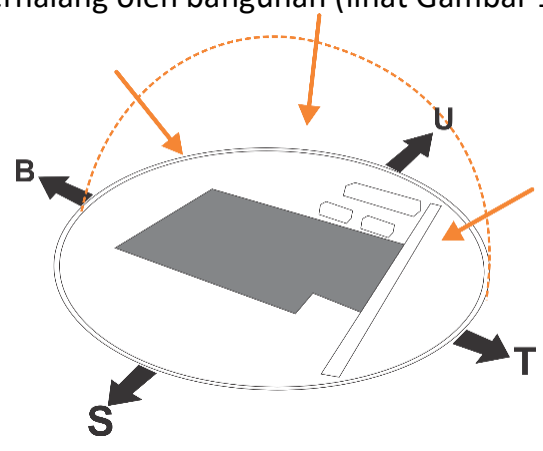

Gambar 1. Analisis Matahari Sumber : analisis, 2019

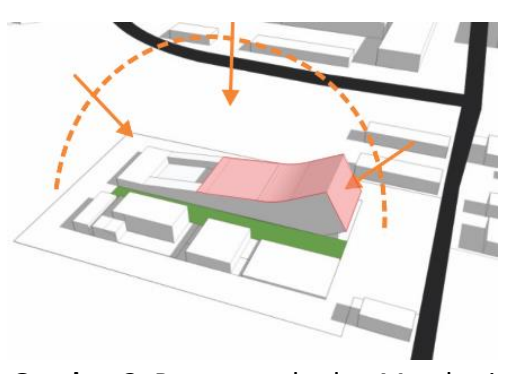

Gambar 2. Respon terhadap Matahari Sumber : analisis, 2019 
Memberikan sedikit bukaan pada bagian timur dan barat sehingga intensitas panas yang dihasilkan terhadap bangunan tidak terlalu tinggi dan atap merespon sesuai iklim tropis untuk mengurangi panas pada bagian atap (Gambar 2).

2. Analisis dan respon angin diperlukan dalam bangunan dimana kondisi site merupakan area persawahan dengan intensitas angin cukup kencang (Gambar 3).

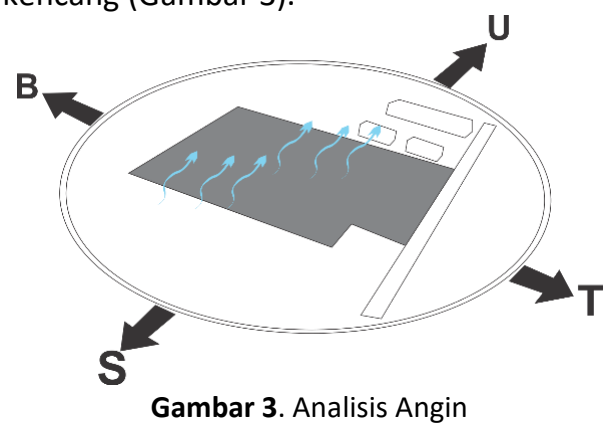

Sumber : analisis, 2019

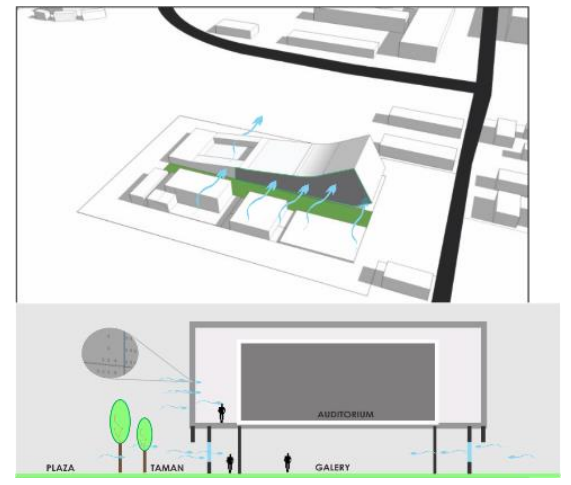

Gambar 4. Respon Angin

Sumber : analisis, 2019

Penggunaan jendela yang dapat dibuka secara horizontal dengan tujuan dapat memasukkan aliran udara dan sekaligus mengatur suhu dalam ruangan. Kontrol aliran udara dengan disain dinding berkisi - kisi untuk merespon iklim tropis (Gambar 4).

3. Analisis dan respon view diperlukan dalam memperlihatkan view sekitar yang berupa persawahan dan perumahan, agar dapat 'dimasukkan' ke dalam ruang (Gambar 5).

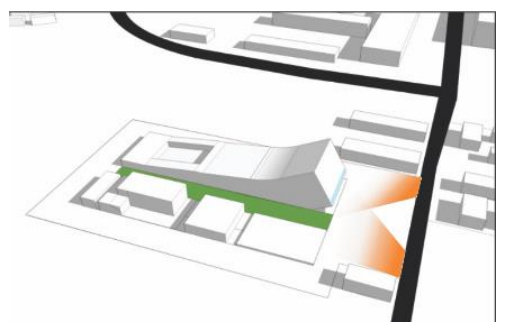

Gambar 5. Analisis dan Respon View insite Sumber : analisis, 2019
Merespon view ke dalam dari arah jalan agar terlihat jelas, sehingga dapat memberikan efek keindahan taman ke dalam ruang. Pada bangunan bagian depan dibuat lebih tinggi dengan bentuk yang iconic sehingga bangunan memiliki daya pikat dengan bangunan yang dibuat lebih ke dalam (Gambar 6).

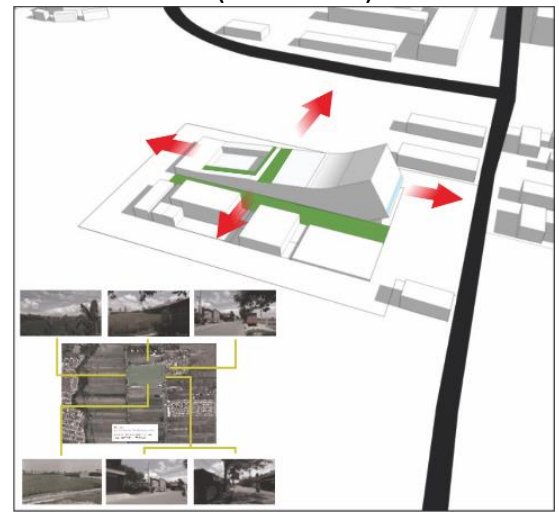

Gambar 6. Analisis dan Respon View outsit Sumber : analisis, 2019

Menciptakan roof garden untuk mendukung sustainable bangunan dimana menciptakan suasana sejuk dari arah luar ke dalam bangunan. Roof garden dapat diakses untuk mendukung view secara maksimal pada kawasan.

4. Analisis dan respon vegetasi diperlukan dalam site, untuk memberikan suasana sejuk pada luar dan dalam bangunan (Gambar 7 dan 8).

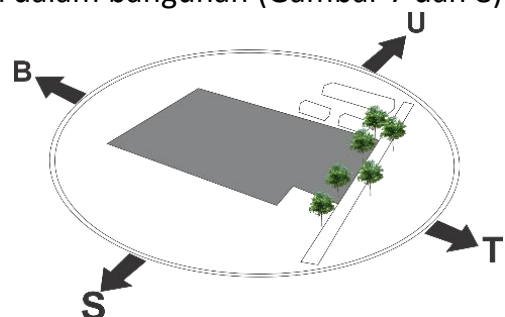

Gambar 7. Analisis dan Respon vegetasi Sumber : analisis, 2019

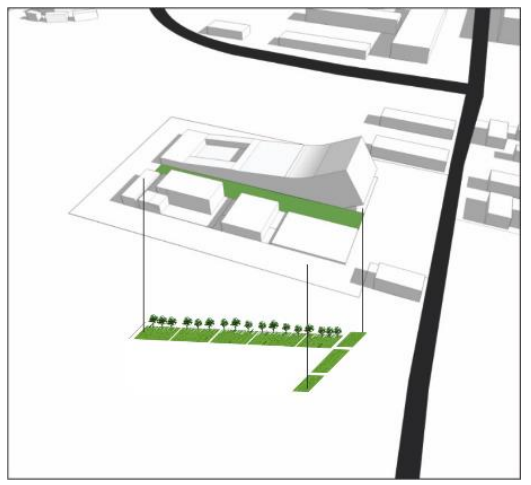

Gambar 8. Analisis dan Respon vegetas Sumber : analisis, 2019

Penambahan vegetasi berupa pepohonan dan tanaman rambat pada bangunan sebagai penyejuk 
dan menambah $\mathrm{O} 2$ pada lingkungan taman budaya dan sebagai peneduh di luar bangunan, dengan pemilihan jenis pepohonan yang rindang dan dan tajuk sedang.

5. Analisis dan respon Infrastruktur dalam site bersumber pada trafo jalan yang dimanfaaatkan sebagai akses jaringan terhadap bangunan (Gambar 9).

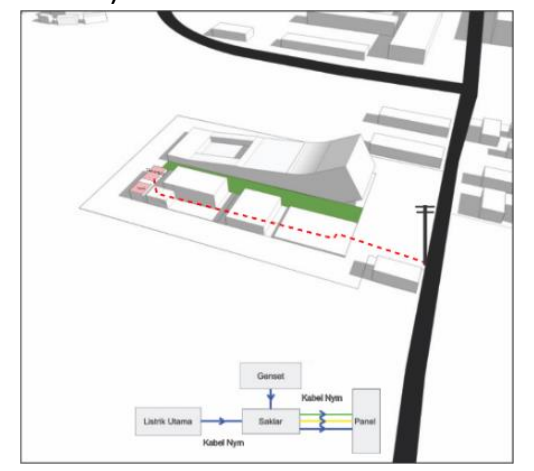

Gambar 9. Analisis dan Respon infrastruktur Sumber : analisis, 2019

Pada respon infrastruktur, bangunan menggunakan dua sistem tenaga listrik, yaitu pertama dari PLN sebagai sumber utama yang kemudian didistribusikan ke jaringan ruang panel dan kedua menggunakan generator sebagai sumber pembangkit listrik cadangan ketika terjadi masalah pada jaringan utama.

\section{Konsep Desain}

Konsep sustainable design menekankan konsep keseimbangan ekologis, sosial, dan ekonomi. Tiga hal ini menjadi dasar agar terwujudnya kenyaman, interaksi sosial di dalam dan di luar bangunan, pengurangan dampak pembuangan limbah bangunan terhadap lingkungan. Penerapan konsep tersebut dapat dilihat pada beberapa proses penerapan bentuk bangunan, fasad bangunan, system kerja air, struktur, utilitas bangunan yang dapat dilihat pada penjelasan dibawah ini :

\section{Konsep Gubahan}

Bentuk massa bangunan memanfaatkan bentuk site persegi dan membaginya menjadi 2 area hijau dan bangunan sesuai dengan regulasi, sehingga keseimbangan secara bangunan dengan green area tercapai (Gambar 10).

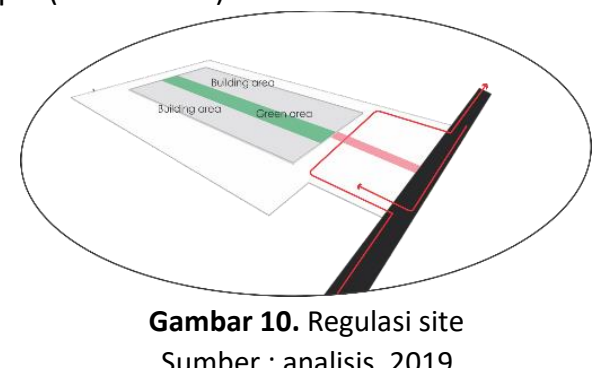

Sumber : analisis, 2019
Massa bangunan dibagi menjadi 3 menurut zoning untuk mempermudah pembeda antara bangunan utama dan pendukung sehingga terjalin interaksi antara kedua bangunan (Gambar 11).

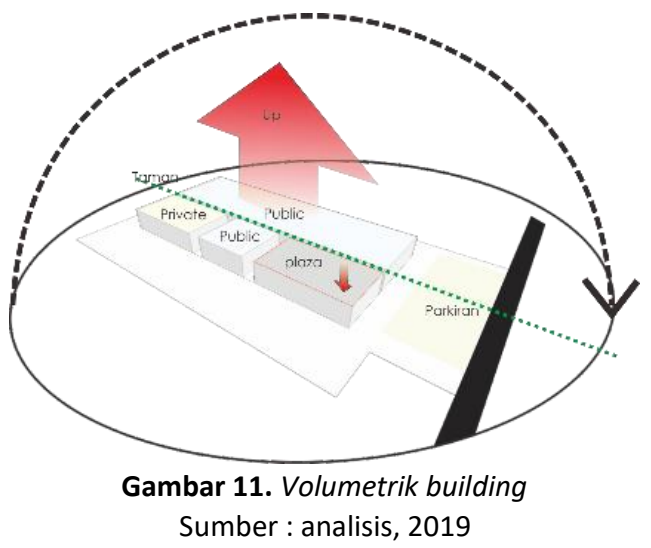

Penambahan pada bangunan diterapkan pada sisi depan massa sesuai dengan jumlah lantai dan fungsi. Penambahan dan pengurangan massa dipergunakan untuk merespon analisis matahari, sehingga diperoleh atap yang mendukung iklim tropis (Gambar 12).

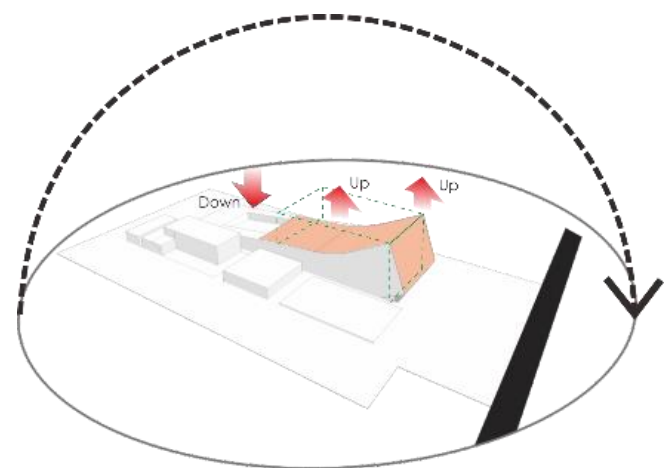

Gambar 12. Penambahan dan pengurangan Sumber : analisis, 2019

\section{Konsep Fasad}

Penerapan sirkulasi udara yang masuk dengan akses jendela semi terbuka yang dibuat persegi pada sisi bagian depan yang di kelilingi oleh secondary skin. Dan sisi bagian samping dibuat pola gunungan wayang berupa skin acp berpola kayu. Sehingga memberikan nilai estetika visual pada fasade (Gambar 13).

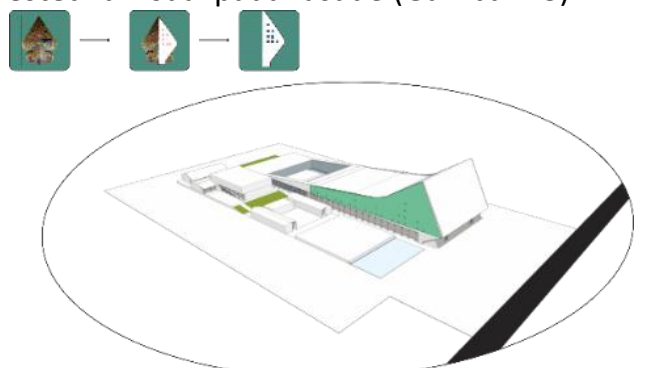

Gambar 13. Fassad bangunan Sumber : analisis, 2019 


\section{Konsep Water Conservation}

Sistem pengelolaan air yang digunakan dalam upaya efisiesi penggunaan air yang berlebihan dan pengemasan kembali sisa dari air wudhu dan penyaringan air hujan kemudian difilterisasi dan dimanfaatkan kembali (Gambar 14 dan 15).

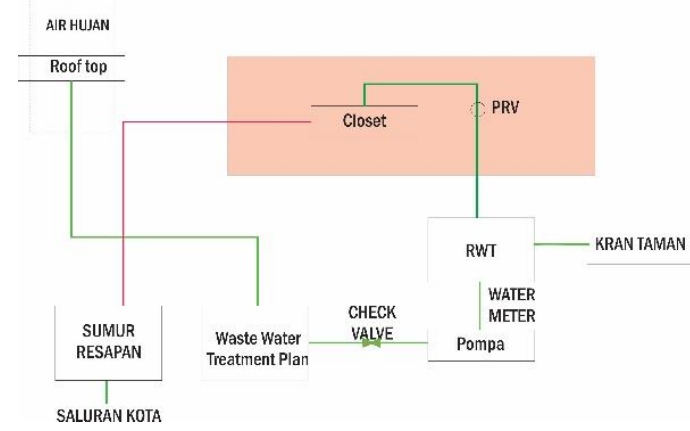

Gambar 14. Pengolahan Air Hujan Sumber : analisis, 2019

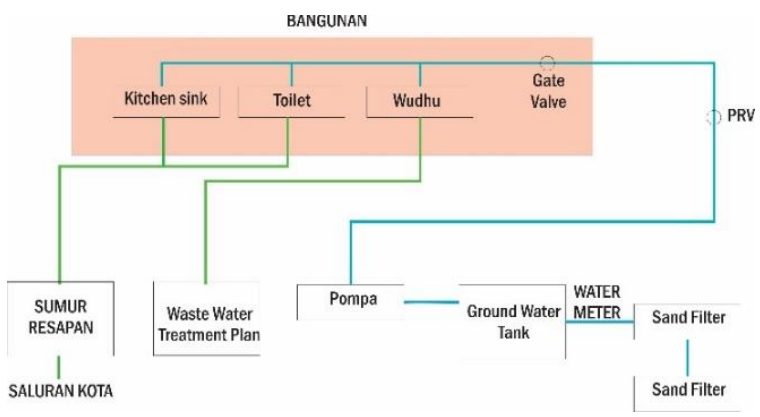

Gambar 15. Pengolahan Air Bersih Sumber : analisis, 2019

\section{Konsep Struktur Bangunan}

Struktur bangunan menggunakan sistem grid dengan alasan ketahanan struktur yang cukup kuat untuk bangunan. Konsep struktur pada taman budaya ini mengunakan pondasi footplat pada bagian bangunana bertingkat, seperti pada bangunan utama dan bangunan penunjang bagian kantin dan cafe yang berada di lantai dua. Sedangkan system penguat pada bagian lantai atas menggunakan kolom balok cor beton, atap menggunakan roof garden dan penggunaan rangka atap baja IWF (Gambar 16).

\section{Konsep Utilitas Bangunan}

Konsep utilitas pada bagian keselamatan bangunana menggunakan hydrant yang diletakkan pada titik-titik tertentu di luar maupun dalam bangunan. Pada system distribusi air bersih menggunkan upfeed dan pengolahan air kotor menggunkan system sewage. Untuk system keamanan menggukan CCTV. Penghawaan pada bangunan menggunakan penghawaan alami pada bagian gallery, lobby, kantin, café dan ruang lain. Sedangkan pada bagian penghawaan buatan menggunakan $A C V R V$ pada ruang tunggu, auditorium dan perpustakaan dan AC split pada ruangan pengelola. Distribusi listrik bersumber pada PLN dan generator. Eksplodametri utilitas dapat dilihat pada gambar 18.

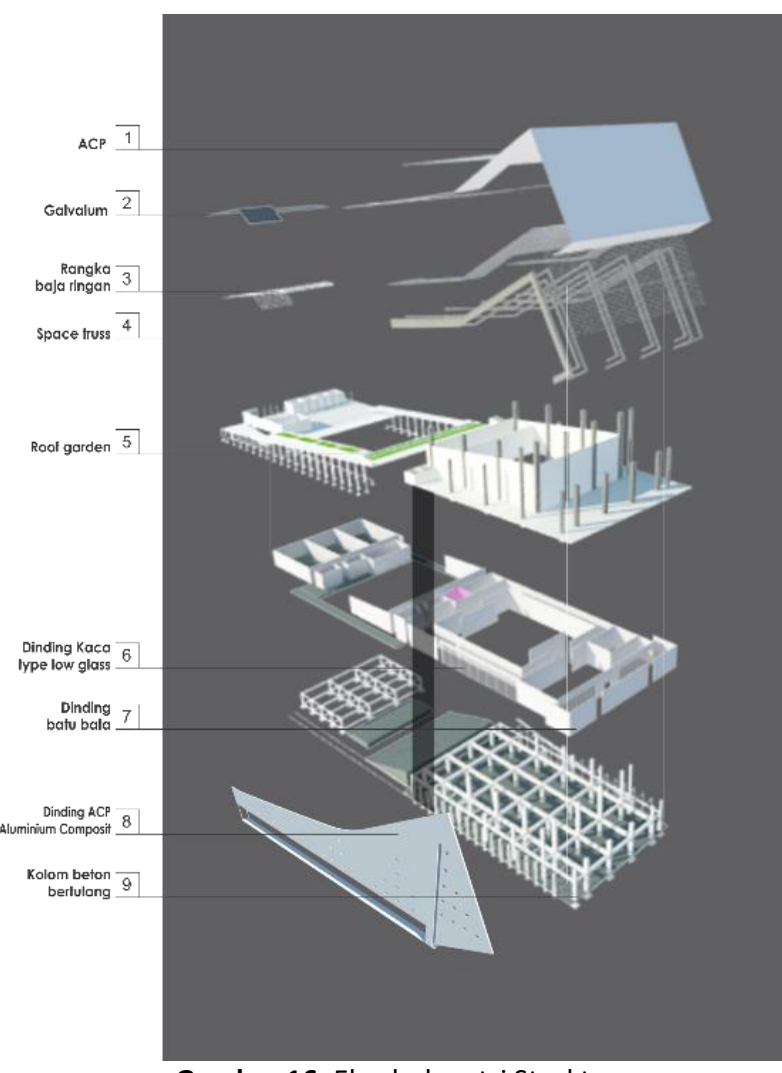

Gambar 16. Eksplodanetri Struktur

Sumber : analisis, 2019

\section{Konsep Sustainable Design}

Konsep sustainable design pada taman budaya dapat dilihat pada gambar 17 . Konsep tersebut merupakan proses analisis dalam penerapan sustainable design pada bangunan dan site sehingga arah dan pembagian ruang dapat terbaca jelas (Kim,Brenda Ringdon,1998).
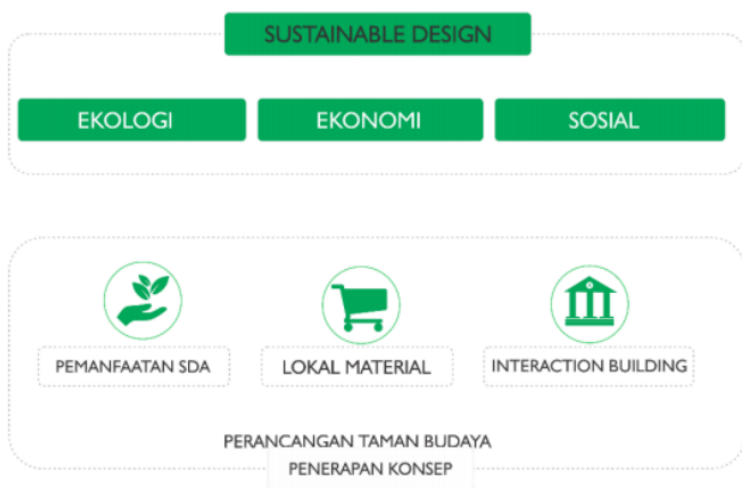

Gambar 17. Konsep sustainable Sumber : analisis, 2019

SINEKTIKA Jurnal Arsitektur, Vol. 16 No. 1 Januari 2019 


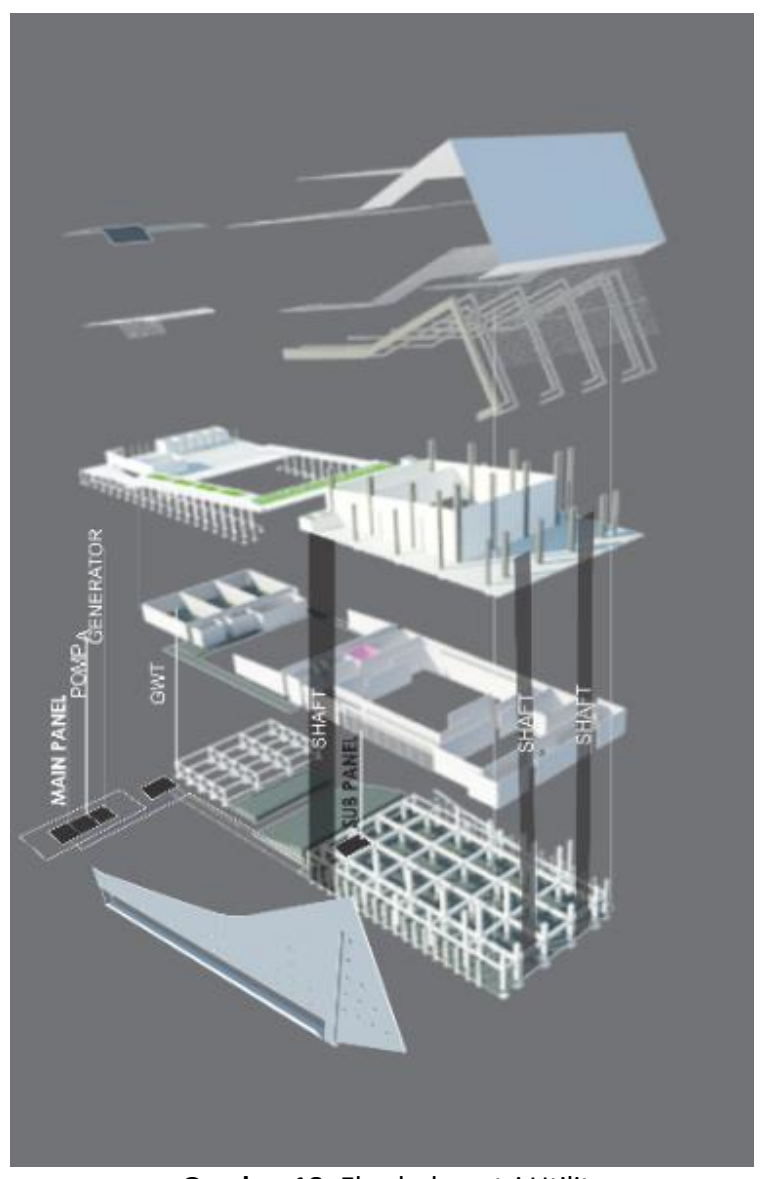

Gambar 18. Eksplodametri Utilitas

Sumber : analisis, 2019

Pada gambar 19 penerapan konsep sustainable terhadap tapak serta pembagian massa sesuai fungsi bangunan. Pembagian fungsi bangunan disusun berdasarkan zonasi yang sudah dibuat sesuai konsep sustainable design.

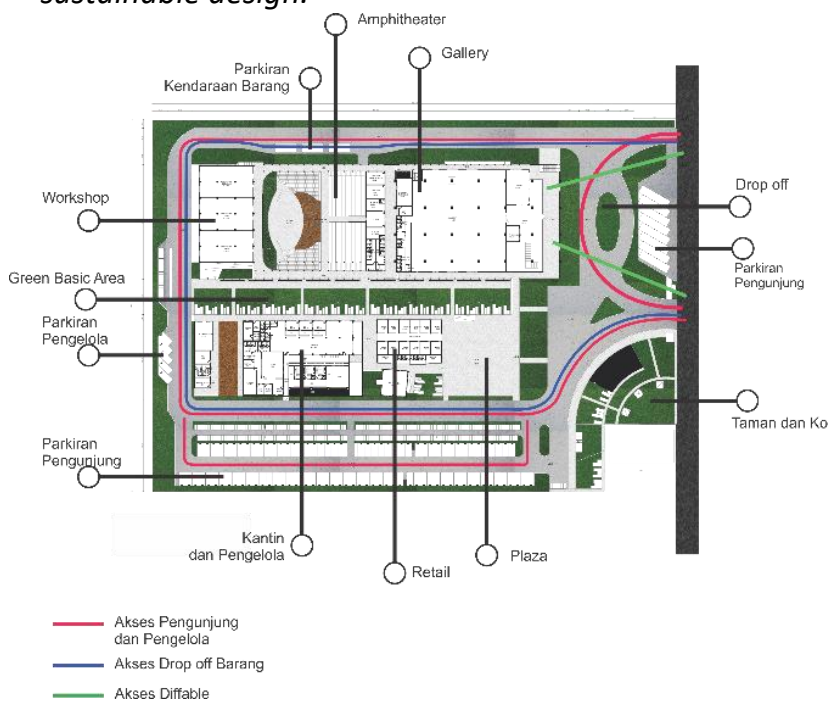

Gambar 19. Aplikasi sustainable Sumber : analisis, 2019

Bangunan 3D di taman budaya dengan penerapan konsep sustainable design terlihat pada gambar 20.

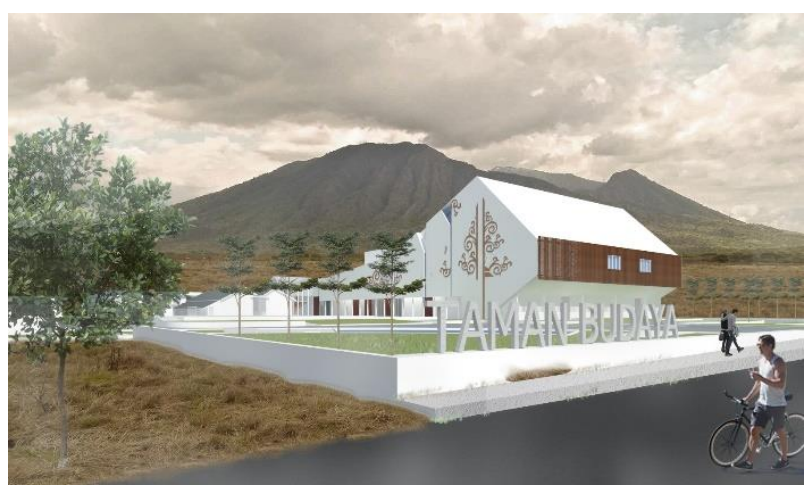

Gambar 20. Bagian - bagian sustainable Sumber : analisis, 2019

\section{KESIMPULAN}

Kesimpulan dari Penerapan konsep sustainable design pada taman budaya di kabupaten klaten terbentuk berdasarkan pemecahan problem secara macro dan secara mikro kemudian di jawab dengan penerapan konsep sustainable design yang dibagi berdasarkan tiga hal yaitu secara ekonomi, social, dan lingkungan. Kemudian diAnalisis berdasarkan iklim lokasi tapak untuk menentukan arah bangunan dan bentukkan massa yang dibagi berdasarkan zonasi, kemudian zonasi bangunan yang diolah menjadi pembagian kebutuhan ruang dimana dari pembagian ruang tersebut saling terkait antara bangunan satu dengan bangunanlain. Dengan penerapan sustainable secara lingkungan untuk menata landscape bangunan, mengolah air sehingga tidak terjadi keborosan pada penggunaan air dan air yang dibuang tidak mencemari area sekitar, dan pemilihan material local seperti bata ekspos yang dikombinasikan dengan material modern berupa acp dan dinding kaca. Secara social memberikan interaksi aktifitas taman budaya dengan masyarakat. Dan secara ekonomi memberikan akses penghubung dengan memfasilitasi berupa retail sehingga perolehan keuangan baik dari pihak masyarakat maupun pemerintah saling menguntungkan. Fassad bangunan dibuat ukiran gunungan wayang.

\section{DAFTAR PUSTAKA}

Djamal (2005). Tantangan Lingkungan dan Lansekap hutan kota, Jakarta, Bumi Aksara.

Eppik, Andreas (2013). The Eppik Model and The Psychological Analysis of Culture http://www.environmentalscience.org/sustaina bility.

Kim, Jong-Jin., Brenda Ringdon (1998). Introduction to Sustainable Design, University Ave, Ann Arbor: National Pollution Prevention Center for Higher Education. 
Kurniasih, Sri (2003), Evaluasi Tentang Penerapan Prinsip Berkelanjutan (Sustainable Architecture), Universitas Budi Luhur, Jakarta

McLennan, Jason F. (2004), The Philosophy of Sustainable Design

Nasir,Ratna Y. (2004). Perangkat Penilaian Bangunan Hijau untuk Bangunan Baru Versi 1.3.Jakarta : GREEN BUILDING COUNCIL INDONESIA http://bliexperience.wordpress.com/2016/02/24/pri nsip-pengertian-sustainable-design/

http://www.academi.edu/9308770/pengertian_pera ncangan_menurut_bin_ladjamudin

http://www.goggle.co.id/amp/s/lutfihutama.wordpre ss.com/2017/03/02/perencanaan-

danperancangan-arsitektur/amp

http://www.google.co.id/amp/s/materiips.cm/penge rtian-budaya/amp 